\title{
Complete analytical procedure to assess the response of a frame submitted to a column loss
}

\author{
Clara Huvelle, Van-Long Hoang, Jean-Pierre Jaspart, Jean-François Demonceau \\ University of Liège
}

\section{Corresponding author:}

Jean-François Demonceau, Chemin des Chevreuils, 1 B52/3, 4000 Liège - Belgium Phone: +3243669358 - e-mail : jfdemonceau@ulg.ac.be

\section{$\underline{\text { Abstract }}$}

The present paper gives a global overview on recent developments performed at the University of Liege on structural robustness of buildings for the specific scenario "loss of a column". In particular, a complete analytical method to assess the response of a 2D frame losing statically one of its columns is presented in details. This method is based on the development of alternative load paths in the damaged structure and takes into account the couplings between the different parts of the structure which are differently affected by the column loss. Also, the validation of the developed method through comparison to experimental and numerical evidences is presented.

Keywords: robustness, column loss, analytical model, steel structures, building structures, exceptional event

\section{Introduction}

Recent events such as natural catastrophes or terrorism attacks have highlighted the necessity to ensure the structural integrity of buildings under an exceptional event. According to Eurocodes and some other national design codes, the structural integrity of civil engineering structures should be guaranteed through appropriate measures and one way to guarantee it is to ensure an appropriate robustness of the structure, which may be defined as the ability of a structure to remain globally stable in case of exceptional event leading to local damages. However, although global design approaches such as the activation of alternative load paths or the key element method are provided in modern codes and standards, no easy-to-apply practical guidelines are provided. The present 
paper reflects recent researches realised at the University of Liege with the objective of proposing such practical guidelines for the activation of alternative load paths in the structure, knowing that this design strategy generally leads to the most economical solutions.

\section{Background}

The behaviour of steel and composite frames under the exceptional event "loss of a column" have been recently investigated through many researches (e.g. from [1] to [13] among others). At the University of Liege, this topic is under investigation since many years using experimental, numerical and analytical approaches [2]. The adopted general philosophy in Liege is to observe the redistribution of the loads in damaged structures through the activation of alternative load paths and to develop analytical methods to predict this redistribution of loads. Knowing how the loads are redistributed, it is possible to estimate whether or not the remaining elements are able to sustain the additional loads coming from this redistribution, without causing a progressive collapse of the entire frame.

Two PhD theses have already been finalised on these topics in Liege (Demonceau [4] and Luu [11]). These theses have contributed to the development of a first analytical method that allows predicting the response of frames submitted to a column loss, and in particular, the associated catenary actions. This initial method has been recently improved and completed. The present paper gives a precise description of this improved analytical procedure.

\subsection{General philosophy}

When a frame is submitted to a column loss, two parts can be identified in the structure: the directly affected part and the indirectly affected part. The directly affected part contains all the beams, columns and beam-to-column joints located just above the lost column (Figure 1). The rest of the structure (i.e. the lateral parts and the storeys under the lost column) is defined as the indirectly affected part.

When the frame loses one of its columns (column AB in Figure 1a), the evolution of the compression force $N_{A B}$ in this element VS the vertical displacement $(u)$ at the top of this column is divided in 3 
phases as illustrated in Figure 1. During phase 1 (from (1) to (2) in Figure 1b), i.e. before the event, the column is "normally" loaded (i.e. the column supports the loads coming from the upper storeys) and the corresponding load is named $\mathrm{N}_{\mathrm{ABnormal}}$.

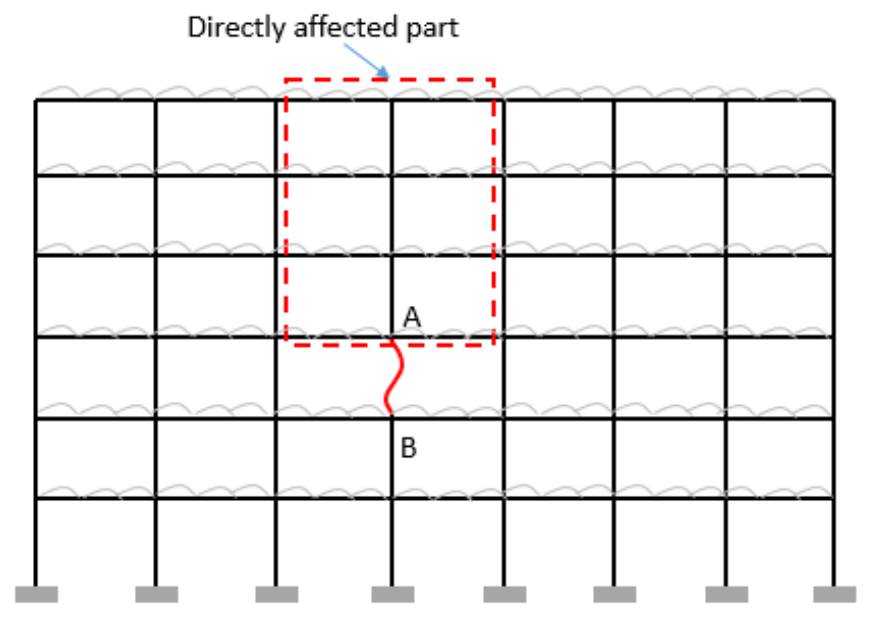

a) Frame description

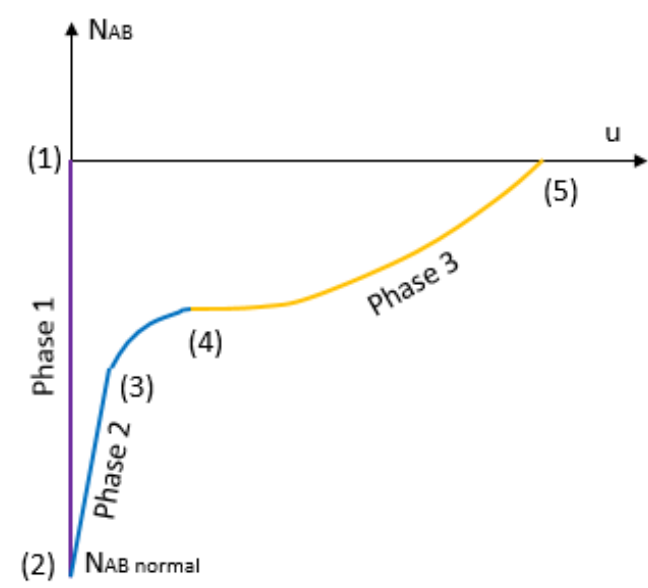

b) Behaviour description

Figure 1. Behaviour of a frame submitted to a column loss

Phase 2 (from (2) to (4) in Figure 1 b) begins when the event occurs and the column progressively loses its axial resistance. During this phase, a plastic mechanism develops in the directly affected part. Each change of slope in the curve of Figure $1 \mathrm{~b}$ corresponds to the development of a new hinge in the directly affected part, until reaching a complete plastic mechanism (point (4) in Figure 1b). Phase 3 (from (4) to (5) in Figure 1b) starts when this plastic mechanism is formed: the vertical displacement at the top of the lost column increases significantly since there is no more first order rigidity in the structure. As a result of these large displacements, catenary actions develop progressively in the beams of the directly affected part, so providing a second-order stiffness to the structure. The role of the indirectly affected part during phase 3 is to provide a lateral anchorage to these catenary actions: the stiffer the indirectly affected part is, the higher the catenary actions will be in the directly affected part. In the extreme situation where the indirectly affected part has no lateral stiffness, then no catenary actions will develop and phase 3 will not develop. 
The behaviour of the actual structure from (2) to (5) (Figure 1b) may be predicted simulating the behaviour of the structure as shown in Figure 2; the frame without the lost column $A B$ is subjected to a concentrated load P going downward and applied at node A.

The objective with the analytical method developed in Liege is to determine a P-u curve reflecting the behaviour of the simulated structure, to estimate the redistribution of loads within the structure during these phases and finally to check whether the structure is able or not to reach point (5), i.e. when $\mathrm{P}=\mathrm{N}_{\mathrm{ABnormal}}$. Indeed, this point is reached only if there is enough resistance and ductility in the damaged structure to sustain these large displacements and associated forces coming from the activation of alternative load paths.

The analytical model presented herein focuses on the behaviour of the frame during Phase 3 (from (4) to (5)), the behaviour of the frame during Phase 2 being easily predicted through classical approaches.
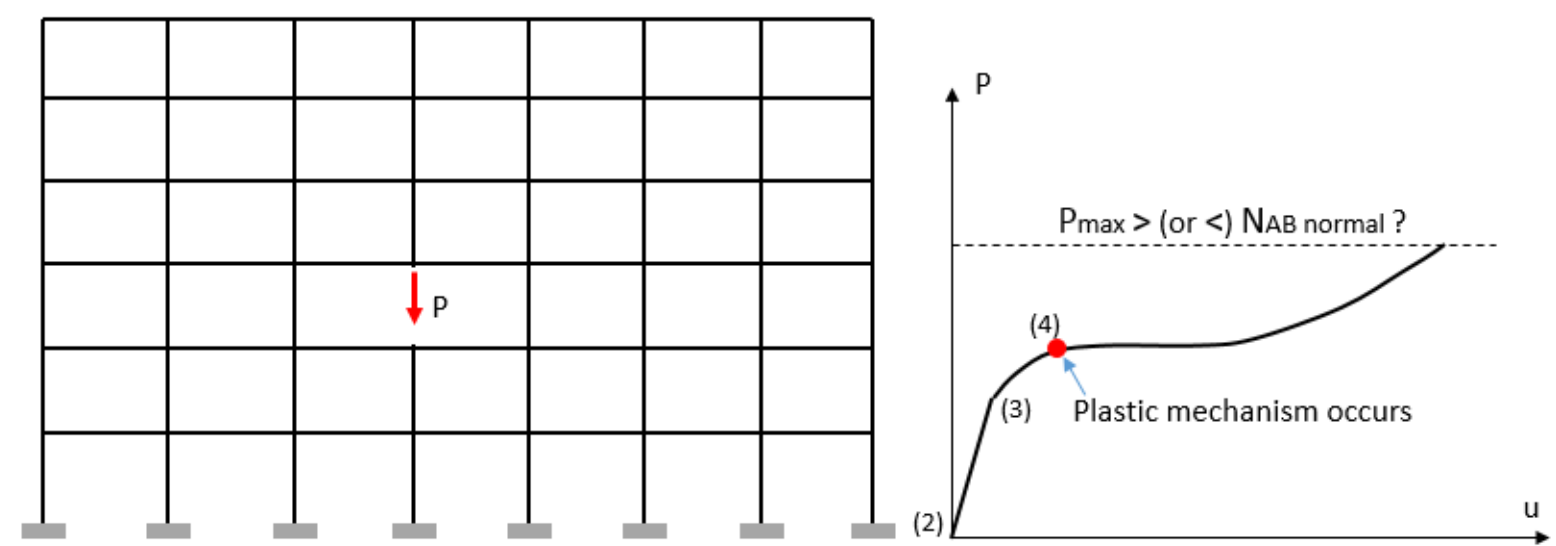

Figure 2. Simulation of the column loss

\subsection{Demonceau model}

In Demonceau thesis [4], an analytical method has been developed that allows predicting the P-u curve during phase 3 (Figure 1) for the case of a 2D structure losing statically one column. The method is focusing on phase 3, i.e. when second order effects are predominant, and is based on the study of a substructure that contains only the lower beams of the directly affected part (Figure 3), identified as the beam where higher tension forces appear. The surrounding structure is simulated by a horizontal spring with a stiffness $\mathrm{K}_{\mathrm{H}}$ (Figure 3 ). This $\mathrm{K}_{\mathrm{H}}$ has a constant value in the model as it is 
assumed that the indirectly affected part remains elastic during phase 3 . Of course, this constitutes a simplification of the actual behaviour of the indirectly affected part as the latter can yield during this phase; the revision of this assumption will be considered in the future developments.

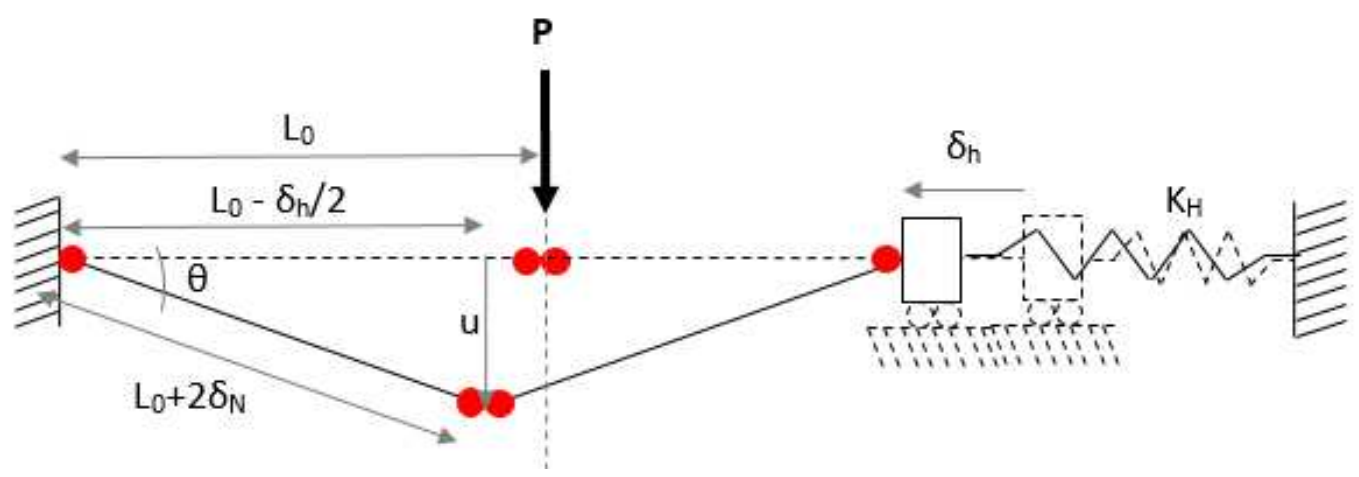

Figure 3. Substructure considered in the Demonceau model [4]

The input data of this method are the following:

- $L_{0}$ : initial length of the beam (Figure 3).

- M-N resistance interaction curve for both hogging and sagging bending in the plastic hinges (located in a beam cross-section or in a joint). These laws can be determined by [14] or [15] for joints and [16] or [17] for beam cross-sections.

- $K_{H}$ : stiffness of the horizontal spring (Figure 3).

- $\mathrm{K}_{\mathrm{N}}$ : axial stiffness of a plastic hinge submitted to both bending and axial forces (defined as the ratio between the axial force $\mathrm{N}$ and the plastic elongation of the hinge $\delta_{N}$ - see Figure 3 ).

During phase 2 , the hinges are only submitted to bending (A-B on Figure 4) while, during phase 3 , they are submitted to both $\mathrm{M}$ and N (B-C on Figure 4). At the very end of phase 3 , they could possibly even only be submitted to $\mathrm{N}$ (point $\mathrm{C}$ on Figure 4). The relation between $\mathrm{N}$ and $\delta_{\mathrm{N}}$ is assumed to be linear and totally defined by this parameter $\mathrm{K}_{\mathrm{N}}$ (Figure 4). This assumption has been validated through numerical and experimental tests [4]. 

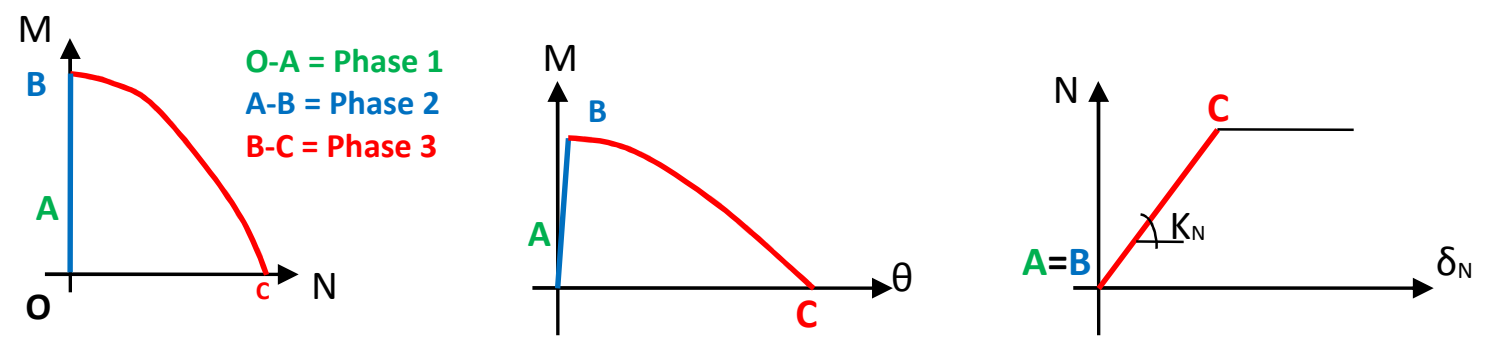

Figure 4. Behaviour of the yielded sections

The unknowns and equations obtained from the study of the substructure given in Figure 3 are reported in Table 1. As the number of equations is equal to the number of unknowns, this system can be easily solved for different values of $u$.

In [4], it is demonstrated that this substructure model is able to reflect accurately the response of a frame further to a column loss if the parameters $\mathrm{K}_{\mathrm{N}}$ and $\mathrm{K}_{\mathrm{H}}$ are appropriately estimated.

As the substructure defined by Demonceau takes into account only one storey of the frame that suffers the column loss, the parameter $\mathrm{K}_{\mathrm{H}}$ should reflect the behaviour of all the structure around, i.e. on the one hand, the storeys of the directly affected part above the lost column, and on the other hand, the indirectly affected part located beside.

Table 1. Unknowns and equations of the Demonceau model

\begin{tabular}{|l|l|}
\hline Unknowns & Equations \\
\hline $\mathrm{u}$ & $\mathrm{u}=$ input data \\
\hline$\theta$ & $\sin (\theta)=\mathrm{u} /\left(\mathrm{L}_{0}+2 \delta_{\mathrm{N}}\right)$ \\
\hline$\delta_{\mathrm{h}}$ & $\cos (\theta)=\left(\mathrm{L}_{0}-\delta_{H} / 2\right) /\left(\mathrm{L}_{0}+2 \delta_{\mathrm{N}}\right)$ \\
\hline$\delta_{\mathrm{N}}$ & $\delta_{H}=\mathrm{F}_{H} / \mathrm{K}_{H}$ \\
\hline $\mathrm{P}$ & $\delta_{\mathrm{N}}=\mathrm{N} / \mathrm{K}_{\mathrm{N}}$ \\
\hline $\mathrm{N}$ & $\mathrm{M}=\mathrm{f}(\mathrm{N})([1]$ or $[17])$ \\
\hline $\mathrm{M}$ & $-0.25 \mathrm{P}\left(\mathrm{L}_{0}-0.5 \delta_{H}\right)+0.5 \mathrm{~F}_{H} \mathrm{U}+2 \mathrm{M}=0$ \\
\hline $\mathrm{F}_{\mathrm{h}}$ & $\mathrm{N}=\mathrm{F}_{H} \cos (\theta)+0.5 \mathrm{P} \sin (\theta)$ \\
\hline
\end{tabular}

However, no analytical procedure was proposed in [4] for this parameter $\mathrm{K}_{\mathrm{H}}$. Also, the parameter $\mathrm{K}_{\mathrm{N}}$ was numerically or experimentally estimated for the validation of Demonceau model in [4], but no analytical prediction model was suggested. 
Therefore, to have a complete analytical procedure, it was necessary to develop analytical models to predict the values of both $\mathrm{K}_{\mathrm{N}}$ and $\mathrm{K}_{\mathrm{H}}$ parameters. This task has been achieved; it is presented in paragraphs 3 and 4 respectively.

\section{Local parameter: $\mathrm{K}_{\mathrm{N}}$}

The $K_{N}$ parameter is defined as a local parameter, because it is linked to the behaviour of the yield zones in the directly affected part. These yield zones can occur in the beam cross-section or in the beam-to-column joint if partial strength joints are used. The developed analytical method is presented for both cases. In this paragraph, the $\mathrm{K}_{\mathrm{H}}$ is assumed to be an input data and only onestorey substructure (as defined previously) is studied.

\subsection{Hinge forming in the beam cross-section}

\subsubsection{Parametrical study}

A range of numerical tests has been performed on the one-storey structure presented in Figure 5. For sake of simplicity, the structure is assumed symmetrical. These simulations have been performed using the homemade software Finelg [18], developed at the University of Liege, taking into account the material and geometric non linearity. The aim was to understand whether the $\mathrm{K}_{\mathrm{N}}$ was a crosssection characteristic, or if there was a coupling between the hinge behaviour and the global structure in which this hinge was developing.

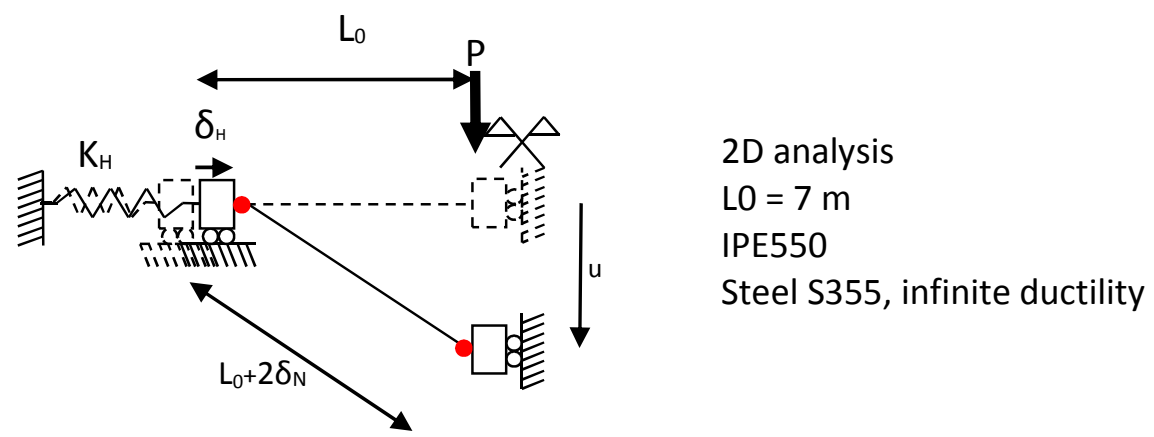

Figure 5. Investigated one-storey substructure to study the plastic elongation of the yield zones

The value of $\delta_{\mathrm{N}}$ was extracted from the numerical results $u$ and $\delta_{\mathrm{H}}$ as follows:

$$
\delta_{N}=\frac{1}{2}\left(-L_{0}+\sqrt{u^{2}+\left(L_{0}-\delta_{H}\right)^{2}}\right)
$$


Although it has been shown by other parametrical studies that the value of $K_{N}$ depends on the value of $\mathrm{E}, \mathrm{f}_{\mathrm{y}}$, and on the cross-section geometrical properties, it appeared that the main parameter influencing the value of $\mathrm{K}_{\mathrm{N}}$ was the parameter $\mathrm{K}_{\mathrm{H}}$ (Figure 6). So, it can be concluded that, in addition to the dependence of $\mathrm{K}_{\mathrm{N}}$ on the cross section characteristic, it also depends globally on the structure in which the hinge develops.

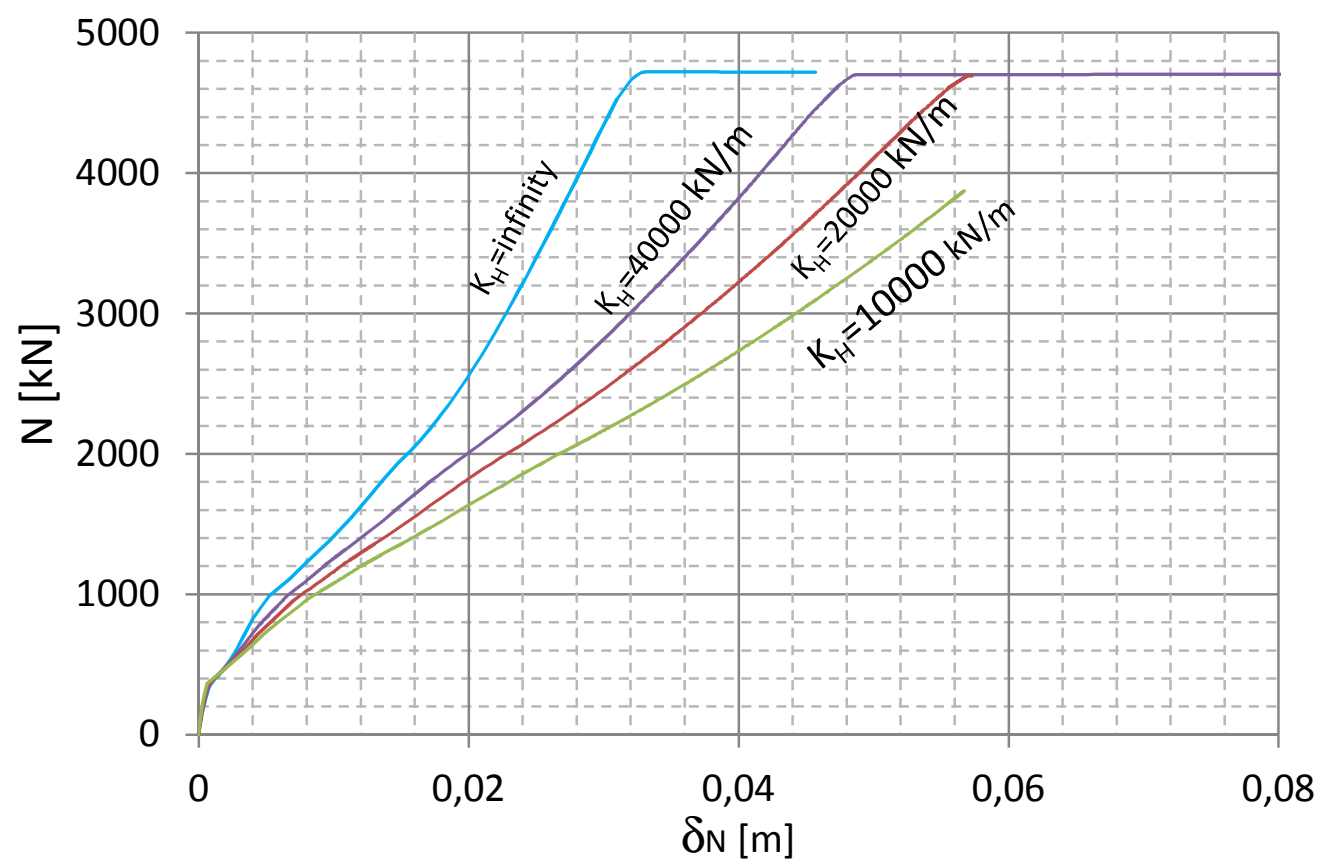

Figure $6 . \mathrm{N}$ vs. $\delta_{\mathrm{N}}$ curves for different values of $\mathrm{K}_{\mathrm{H}}$

\subsubsection{New approach}

To define an analytical model for the prediction of $\mathrm{K}_{\mathrm{N}}$, it is required to define a length for the plastic hinge. This hinge length $L$ is defined according to [19] (see Figure 7).

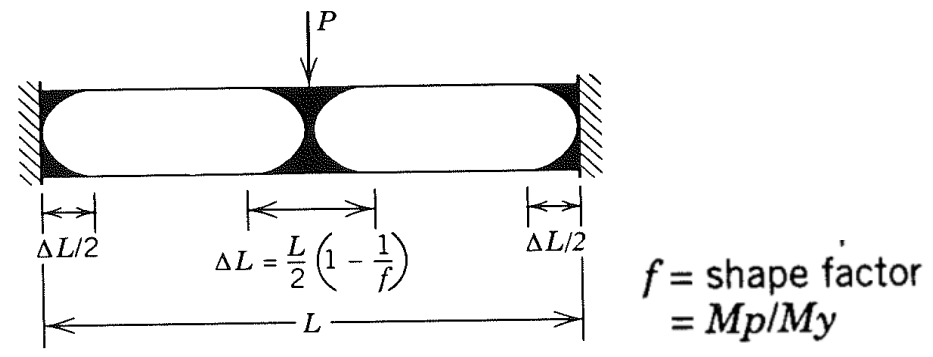

Figure 7. Plastic hinge length definition [19]

Then, the cross-section is fictively divided into 6 parts: 2 parts represent the flanges and 4 parts the web (Figure 8). Finally, the extremities of the beams of the directly affected part can be considered 
as a set of 6 parallel springs submitted to $\mathrm{M}$ and $\mathrm{N}$, assuming that the section at the extremities of these springs remains straight, using the Bernoulli assumption (Figure 8).

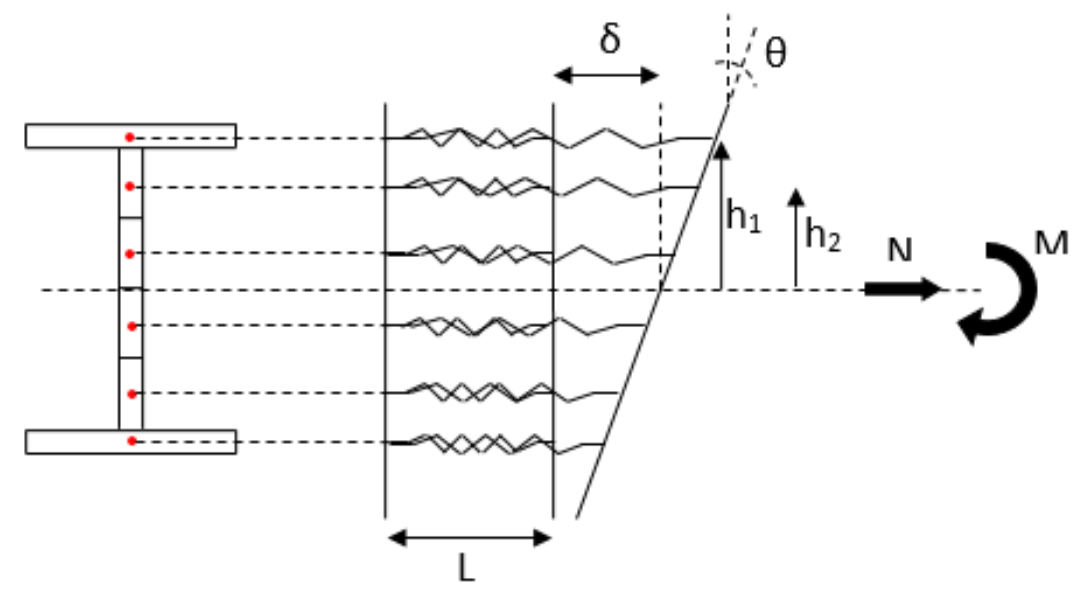

Figure 8. Spring model for the beam cross-section

The force-displacement law of each spring is elastic-perfectly plastic and symmetric in tension and in compression. The resistance of each spring is simply equal to $F_{r d i}=A_{i} f_{y}$ and the stiffness $K_{i}=E A_{i} / L$, where $L$ is the length of the considered hinge, $A_{i}$ represents the section of part " $i$ " and $E$ the Young modulus of the beam material.

When reaching point $\mathrm{B}$ on the $\mathrm{M}-\mathrm{N}$ diagram (Figure 9, beginning of phase 3 ), all the springs are yielded (as a hinge is formed in the considered cross-section) and the springs 3 and 4 on Figure 9 have just reached their maximum elastic elongation, $\mathrm{F}_{\mathrm{rd}} / \mathrm{K}$, so $\delta$ and $\theta$ are known at point $\mathrm{B}$. When going from $B$ to $B 1$, the spring $n^{\circ} 4$ is "unloading" from $-F_{r d}$ to $F_{r d}$, and so remains in the elastic range. During this time, all the other springs are still in the plastic domain, so there is no information on their elongation. Finally at point $B 1$, neither $\delta$ nor $\theta$ can be defined as there are two unknowns ( $\delta$ and $\theta$ ) and only one piece of information (the elongation of spring $n^{\circ} 4$ ). In other words, no relation between $\delta$ and $\theta$ may be found locally. In fact, the missing equation between $\delta$ and $\theta$ comes from the analysis of the global structure in which the hinge forms, so explaining why $\mathrm{K}_{\mathrm{N}}$ depends on $\mathrm{K}_{\mathrm{H}}$. 


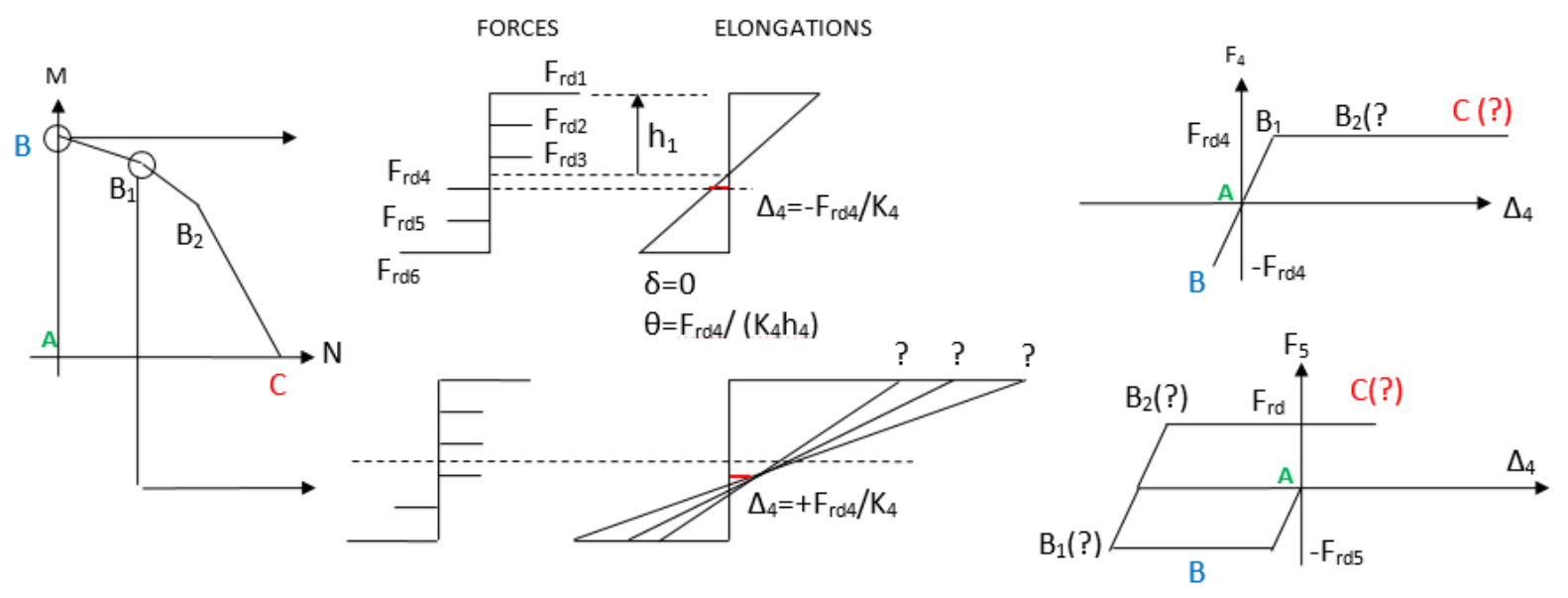

Figure 9. Response of the spring model under $\mathrm{M}$ and $\mathrm{N}$

As there is a coupling between this local parameter $\mathrm{K}_{\mathrm{N}}$ and the global structural response in which the hinge is developing, the local hinge model has to be implemented in the substructure of Demonceau (Figure 10).

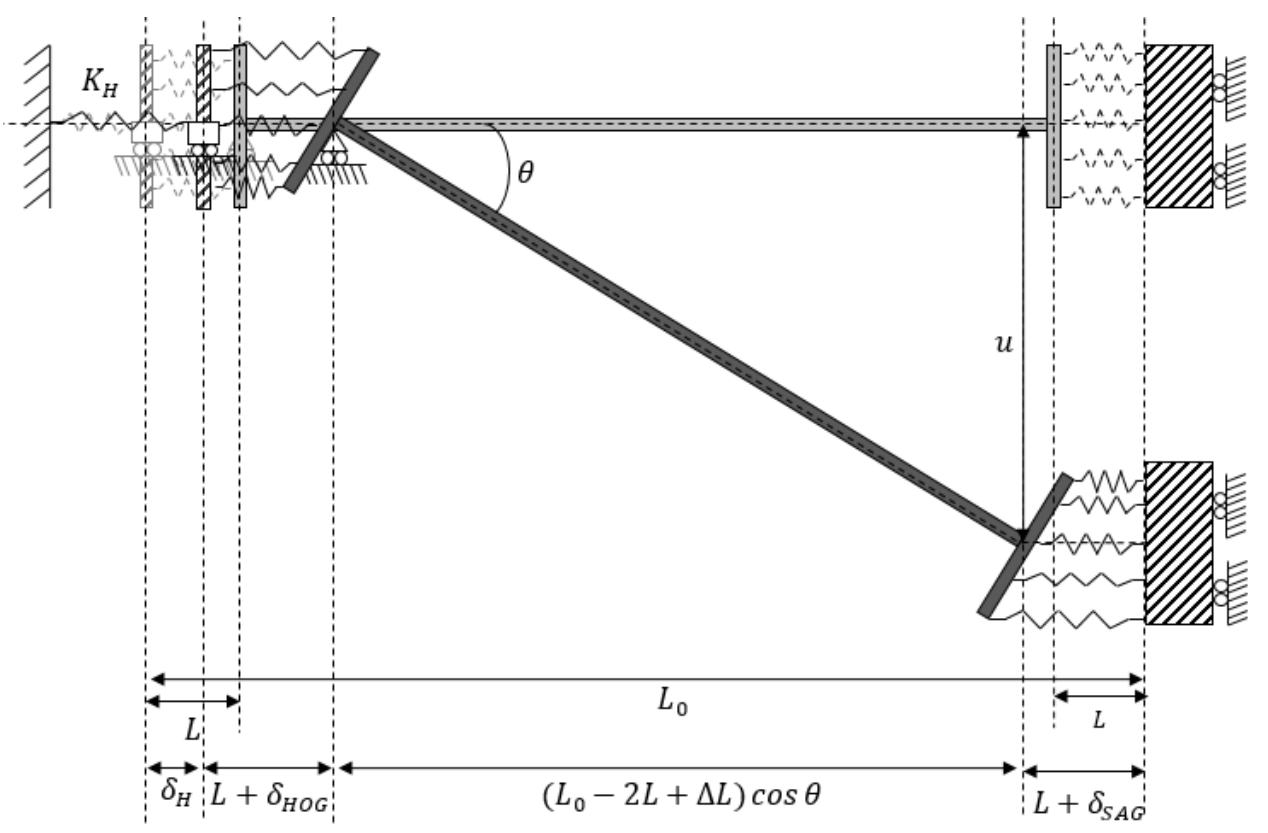

Figure 10. New substructure model

The input data of this new substructure model are:

- The characteristics of the cross section $\left(A, I, W_{\mathrm{el}}, W_{\mathrm{pl}}\right.$, dimensions...), also used for the definition of the spring properties simulating the behaviour of the hinges

$-L_{0}, E, f_{y}, K_{H}$ 
There is no need any more to define a M-N resistance curve or to explicitly define $K_{N}$ linking $N$ to $\delta_{N}$, because these data are implicitly included in the definition of the stiffness and resistances of the springs simulating the hinges at the extremities of the beam.

Table 2. Unknowns and equations for the new substructure model

\begin{tabular}{|l|l|}
\hline Unknowns & Equations \\
\hline $\mathrm{u}$ & $\mathrm{u}=$ input data \\
\hline$\theta$ & $\sin (\theta)=\mathrm{u} /\left(\mathrm{L}_{0}-2 \mathrm{~L}+\Delta_{\mathrm{L}}\right)$ \\
\hline$\delta$ & $\cos (\theta)=\left(\mathrm{L}_{0}-2 \mathrm{~L}-\delta_{\mathrm{H}-2}\right) /\left(\mathrm{L}_{0}-2 \mathrm{~L}+\Delta_{\mathrm{L}}\right)$ \\
\hline$\delta_{\mathrm{H}}$ & $\delta_{\mathrm{H}}=\mathrm{F}_{\mathrm{H}} / \mathrm{K}_{\mathrm{H}}$ \\
\hline$\Delta_{\mathrm{L}}$ & $\Delta_{\mathrm{L}}=\mathrm{F}_{\mathrm{H}}\left(\mathrm{L}_{0}-2 \mathrm{~L}\right) /(\mathrm{EA})$ \\
\hline $\mathrm{M}$ & $\mathrm{M}=\sum \mathrm{F}_{\mathrm{i}} \mathrm{h}_{\mathrm{i}}$ \\
\hline $\mathrm{F}_{\mathrm{H}}$ & $\mathrm{F}_{\mathrm{H}}=\sum \mathrm{F}_{\mathrm{i}}$ \\
\hline $\mathrm{F}_{\mathrm{i}}(\mathrm{i}=[1: 6])$ & $\mathrm{Fi}=\mathrm{f}\left(\delta_{\mathrm{i}}\right)$ \\
\hline$\delta_{\mathrm{i}}(\mathrm{i}=[1: 6])$ & $\delta_{\mathrm{i}}=\delta+\mathrm{h}_{\mathrm{i}} \theta$ \\
\hline $\mathrm{P}$ & $-\mathrm{P}\left(\mathrm{L}_{0}-\delta_{\mathrm{H}}\right)+\mathrm{F}_{\mathrm{H}} \mathrm{u}+2 \mathrm{M}=0$ \\
\hline
\end{tabular}

The equations defined in Table 2 can easily be solved through a mathematical solver, for instance Matlab used for the presented study. Figure 11 shows a comparison between numerical and analytical results for different values of $\mathrm{K}_{H}$. The good agreement obtained between the results validates the proposed approach.

Experimental tests on the deformability of plastic hinges under $\mathrm{M}-\mathrm{N}$ interaction are planned at the University of Liege in 2014; they should confirm the numerical and analytical results.

\subsection{Hinge forming in partial strength joints}

If the beam-to-column joints are partially resistant, then the hinge develops in the joint and not in the beam cross-section. Nevertheless, the approach remains the same as previously described, except that the hinge length is assumed to be equal to 0 . Indeed, the yield zone is localized in the joint, which is assumed to be very short compared to the length of the beam. 


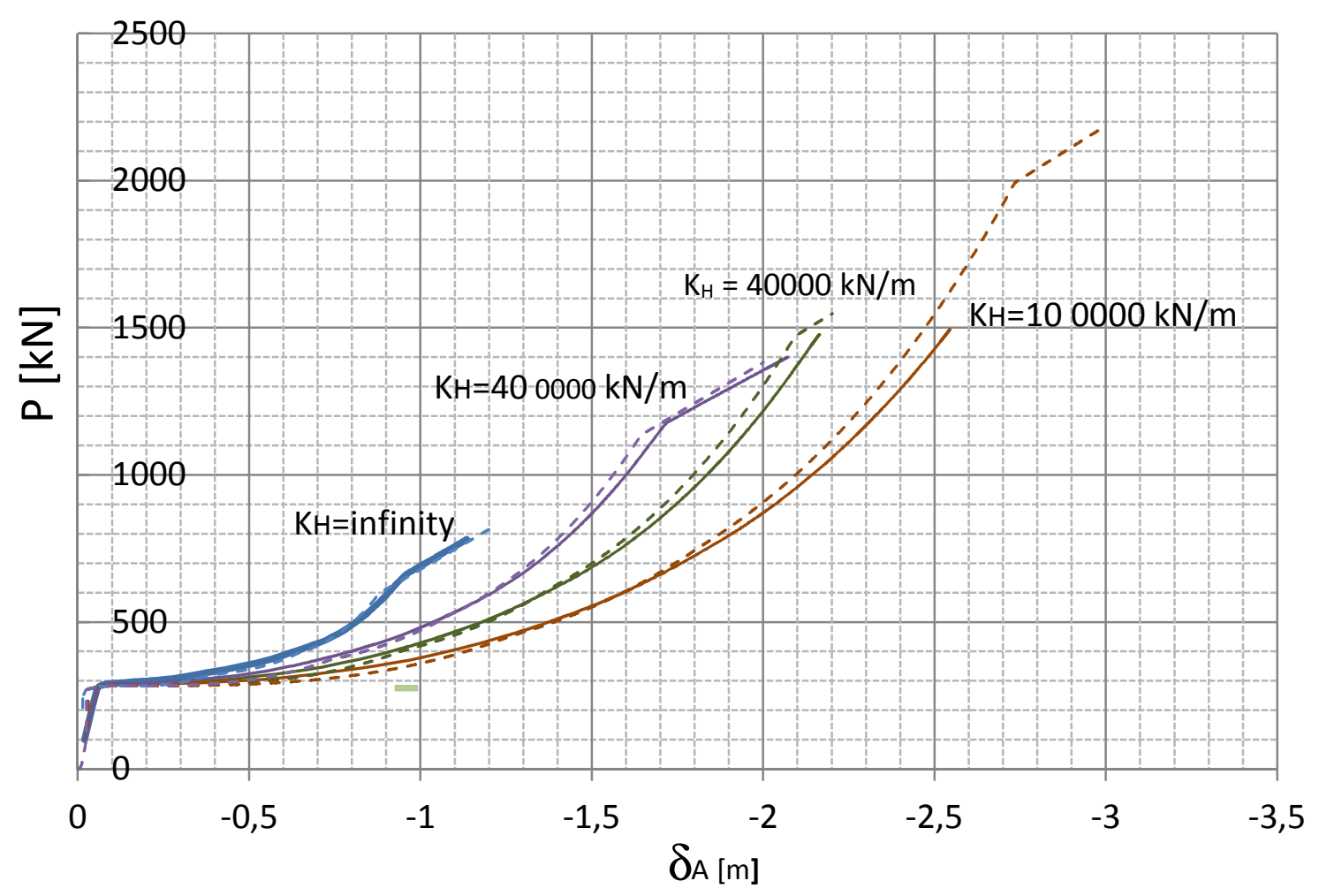

Figure 11. Comparison between numerical (continuous lines) and analytical (dash lines) results for different values of $\mathrm{K}_{H}$

An experimental test has been conducted in Liège in 2008, within the European RFCS project Robustness ([3] and [20]). The test was simulating the static loss of the central support of a composite beam (Figure 12). Horizontal jacks were placed at the extremities of the specimen to simulate the horizontal restraint of the indirectly affected part. More details about this test can be found in [3] (and also in [4]).

At the time of the test, the analytical determination of $K_{N}$ was not available, so the value of $K_{N}$ that had to be introduced in the Demonceau model had been extracted from experimental tests conducted on the joints in isolation at the University of Stuttgart within the same European project Robustness [20].

According to the latest developments in Liege, it is now possible to determine this curve without any experimental or numerical input, as shown hereunder. 

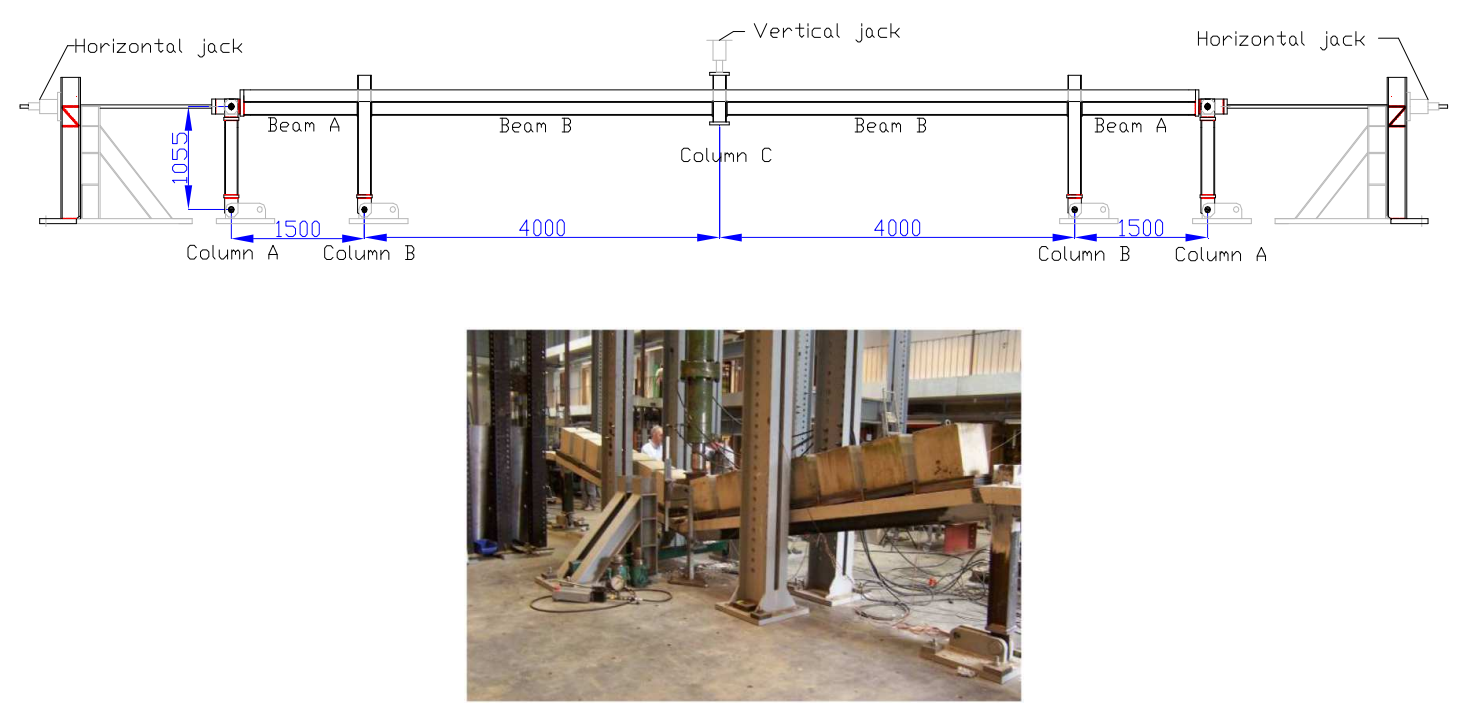

Figure 12. Substructure test conducted at the University of Liege

As for the cross-section, the joint is simulated by springs in parallel. The force-elongation relationship of these springs are elastic perfectly plastic. No limitation in the ductility of the components is assumed for the moment. One spring per joint row is defined, and the characteristics of the spring (stiffness $\mathrm{K}$ and resistance $\mathrm{F}$ ) are determined through the component method, which is recommended in Eurocode 3 and Eurocode 4 for the characterisation of joint properties ([21] and [22]). For the specific joints used for the Liège test, 11 joint rows are identified (Figure 13). For the concrete components (Rows 1, 3, 5 and 7 - see Figure 13), the stiffness is defined according to the formulae developed by Demonceau in [4] (see also [15]) as no rules are presently available for the characterisation of this component in Eurocode 4.

Another difference with the model used for the beam cross-section is that the behaviour of the springs is not symmetric in tension and in compression (Figure 14). For example, the bolts are only activated in tension, while the beam flange is only active in compression as considered in the component method. Also, during the loading, some components could be inactive in the beginning of the loading, under $M$ only (phase 2), and be activated when catenary action develops (phase 3) and conversely. So, it is necessary to define the way these components behave actually. For example, let assume that, during phase 2 , a bolt row is submitted to a negative displacement (meaning that the bolt is in compression). The displacement goes from A to B in Figure 14, without forces in the bolt 
row. At the point $B$, the displacement at the bolt level starts to increase. To be activated, the displacement must return to 0 , and then, the bolt can develop tension forces (Figure 14). Accordingly, for each load step, the loading history in each row has to be known.

(1)
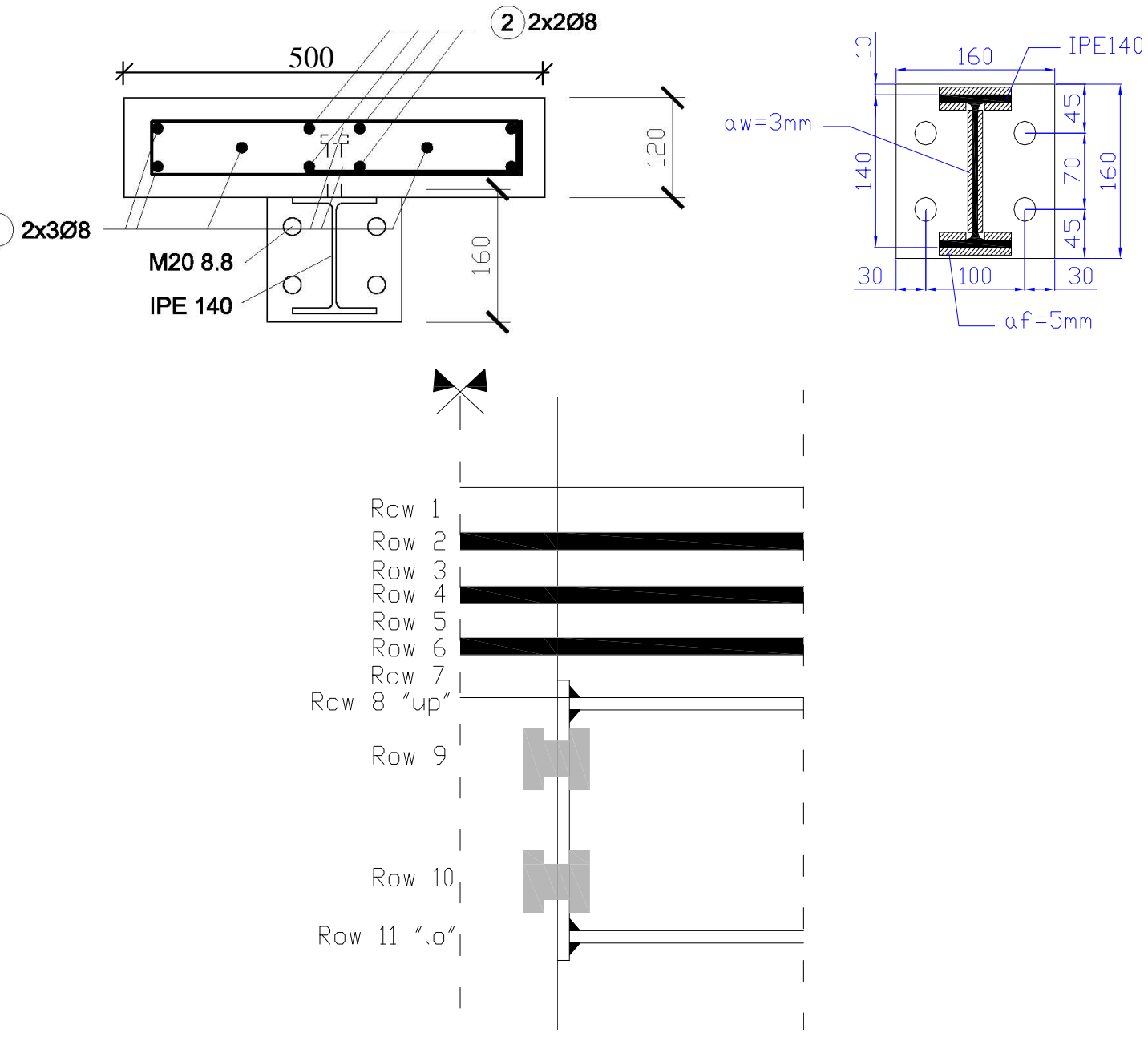

Figure 13. Steel-concrete composite joint configuration of the Liege test

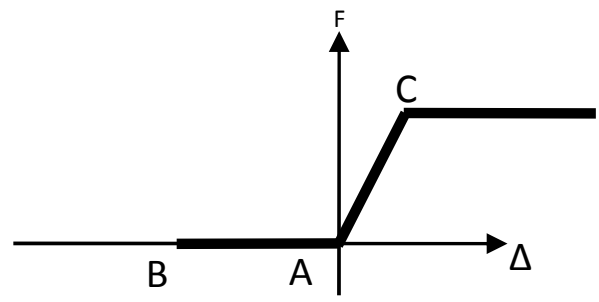

Figure 14. Behaviour law of a joint raw

The input data to be used in the analytical model for the experimental test previously described are:

$-\mathrm{L}_{0}=4 \mathrm{~m}$ 
$-\mathrm{K}_{\mathrm{H}}=8560 \mathrm{kN} / \mathrm{m}$

- Spring characteristics for the joint: $h_{i} F_{i} K_{i}$, given in Table 3, "i" being the number of the joint row under consideration (Figure 13)

Table 3. Properties of the joint row of the composite joint described in Figure 13

\begin{tabular}{|c|c|c|c|c|c|c|c|c|c|c|c|}
\hline ROWS & 1 & 2 & 3 & 4 & 5 & 6 & 7 & 8 & 9 & 10 & 11 \\
\hline $\mathrm{h}_{\mathrm{i}}[\mathrm{mm}]^{(*)}$ & 146.5 & 127 & 116.5 & 106 & 95.5 & 85 & 65.5 & 42.6 & 11 & -59 & -90.6 \\
\hline $\begin{array}{c}\mathrm{K}_{\mathrm{i}} \\
{\left[10^{3} \mathrm{kN} / \mathrm{m}\right]}\end{array}$ & 2173.5 & 85.47 & 2173.5 & 85.47 & 2173.5 & 85.47 & 2173.5 & 1453.8 & 200.13 & 200.13 & 145.8 \\
\hline $\mathrm{F}_{\mathrm{i}+}[\mathrm{kN}]$ & 0 & 66.35 & 0 & 66.35 & 0 & 66.35 & 0 & 0 & 224.22 & 91.55 & 0 \\
\hline $\mathrm{F}_{\mathrm{i}-[\mathrm{kN}]}$ & -340.8 & 0 & -183.5 & 0 & -183.5 & 0 & -340.8 & -374.8 & 0 & 0 & -374.8 \\
\hline \\
${ }^{(*)}: \mathrm{h}_{\mathrm{i}}$ is the distance from row $i$ (Figure 13) to the neutral axis (see Figure 9) \\
\hline
\end{tabular}

Solving the system of equations as given in Table 4, the response of the tested substructure can be analytically predicted. The results of the analytical method are compared with the experimental ones in Figure 15.

It can be seen that the analytical curve fits correctly with the experimental curve during phase 3 , which is the phase under investigation. This validates the so-proposed model.

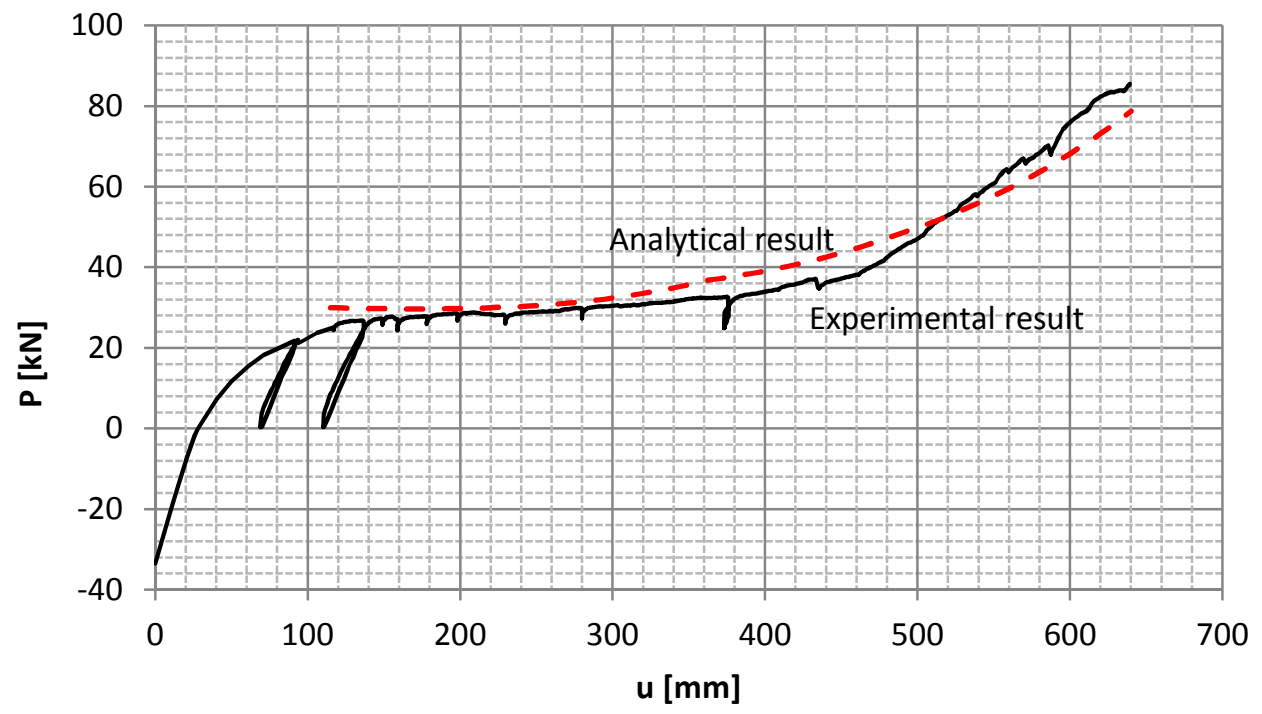

Figure 15. Comparison between the analytical prediction and the test result 
Table 4. Unknowns and equations to be considered for the Liege test

\begin{tabular}{|c|c|}
\hline Unknowns & Equations \\
\hline $\mathrm{u}$ & $\mathrm{u}=$ input data \\
\hline$\theta$ & $\sin (\theta)=u / L_{0}$ \\
\hline$\delta_{S A G}$ & $L_{0}(\cos (\theta)-1)+\delta_{H}+\delta_{S A G}+\delta_{H O G}=0$ \\
\hline$\delta_{\text {HOG }}$ & $\mathrm{F}_{\mathrm{H}}=\sum \mathrm{F}_{\mathrm{iSAG}}$ \\
\hline $\mathrm{F}_{\mathrm{H}}$ & $\mathrm{F}_{\mathrm{H}}=\sum \mathrm{F}_{\mathrm{iHOG}}$ \\
\hline$\delta_{H}$ & $\delta_{H}=F_{H} / K_{H}$ \\
\hline MHOG & $\mathrm{M}_{\mathrm{HOG}}=\sum \mathrm{F}_{\mathrm{HOOG}} \mathrm{h}_{\mathrm{i}}$ \\
\hline $\mathrm{M}_{\mathrm{SAG}}$ & $\mathrm{M}_{\mathrm{SAG}}=\sum \mathrm{F}_{\mathrm{iSAG}} \mathrm{h}_{\mathrm{i}}$ \\
\hline $\mathrm{F}_{\mathrm{iHOG}}(\mathrm{i}=[1: 11])$ & $F_{i H O G}=f\left(\delta_{i H O G}\right)$ \\
\hline $\mathrm{F}_{\mathrm{iSAG}}(\mathrm{i}=[1: 11])$ & $F_{i S A G}=f\left(\delta_{i S A G}\right)$ \\
\hline$\delta_{\text {iHOG }}(i=[1: 11])$ & $\delta_{i H O G}=\delta_{H O G}+h_{i} \theta$ \\
\hline$\delta_{\text {iSAG }}(i=[1: 11])$ & $\delta_{i S A G}=\delta_{S A G}-h_{i} \theta$ \\
\hline$P$ & $\mathrm{P}\left(\mathrm{L}_{0} \cos (\theta)\right)\left(\mathrm{F}_{\mathrm{H}} \mathrm{u}+\mathrm{M}_{\mathrm{HOG}}-\mathrm{M}_{\mathrm{SAG}}\right)=0$ \\
\hline
\end{tabular}

\section{Global parameter: $\mathrm{K}_{\mathrm{H}}$}

\subsection{Existence of the coupling effects}

In previous developments conducted in Liege (and in particular by Demonceau - Section 2.2), the substructure defined to study phase 3 was composed only of the lower beam of the directly affected part, i.e. the beams just above the lost column. The rest of the structure (i.e. the indirectly affected part) was only represented by one horizontal spring (see Figure 3).

However, this substructure is only valid if the compression force in the column just above the lost one remains constant during the all duration of phase 3 , which is not always the case, as it has been demonstrated in [10] and [7]. Indeed, important coupling effects between the storeys of the directly affected part and also between the directly and the indirectly affected parts may develop and these effects should be considered into the developed model.

The coupling effects between the directly and the indirectly affected part could be taken into account through an appropriate definition of $K_{\mathrm{H}}$ while, for the couplings between the storeys of the directly affected part, it is just as if a vertical spring was missing in the substructure defined by 
Demonceau, i.e. a spring that could simulate the effect of the upper storeys of the directly affected part.

Accordingly, a general approach has been developed to take into account these coupling effects. A first method is presented in [8] without taking into account the effects of $K_{N}$ on these couplings. The next paragraph will describe precisely the complete analytical method taking into account the effect of $\mathrm{K}_{\mathrm{N}}$.

\subsection{Complete analytical method}

To consider all the couplings between the directly and indirectly affected parts, it is necessary to include all the storeys in the substructure model. So, the substructure defined by Demonceau is generalized for all the storeys of the directly affected part (Figure 16) and the effects of $\mathrm{K}_{\mathrm{N}}$ are added to this generalized substructure by considering the extremities of the beams with springs in parallel. On the other hand, the influence of the indirectly affected part is taken into account by considering horizontal springs at each extremities of the so-defined substructure.

The springs simulating the restraint of the indirectly affected part are assumed as fully elastic as the indirectly affected part is assumed to be perfectly elastic (i.e. as assumed in Demonceau model - see Section 2.2). The horizontal displacement $\delta_{H i}$ at the storey $i$ is defined as follows: $\delta_{H i}=\sum s_{i j} F_{H j}$, in which the coefficients $\mathrm{s}_{\mathrm{ij}}$ form the flexibility matrix of the indirectly affected part (i.e. $\mathrm{s}_{\mathrm{ij}}$ is the horizontal displacement at the level $\mathrm{i}$ when a unitary horizontal force acts at the level $\mathrm{j}$ - see Figure 17 ) and $\mathrm{F}_{\mathrm{Hj}}$ is the horizontal load applied at storey j. In Figure 17, $\mathrm{s}_{\mathrm{l}, \mathrm{ij}} \mathrm{S}_{\mathrm{r}, \mathrm{ij}}$ are respectively the displacements of the left (" $l$ ") and the right (" $r$ ") sides of the indirectly affected parts, then $s_{i j}=s_{1, j j}+s_{r, j i}$. 


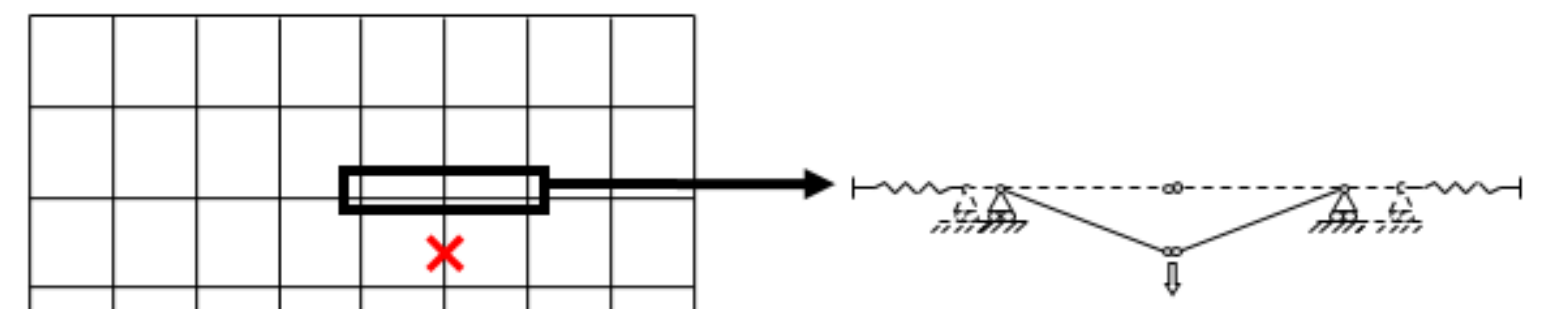

Demonceau substructure
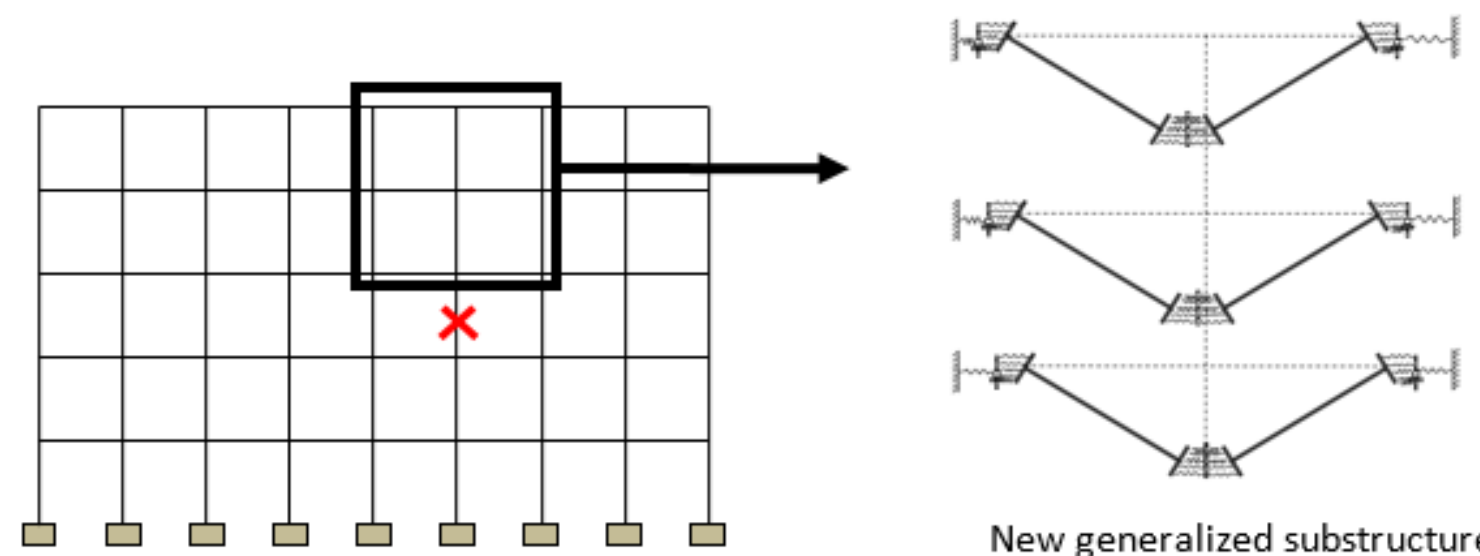

New generalized substructure

Figure 16. Definition of a new substructure

(a)

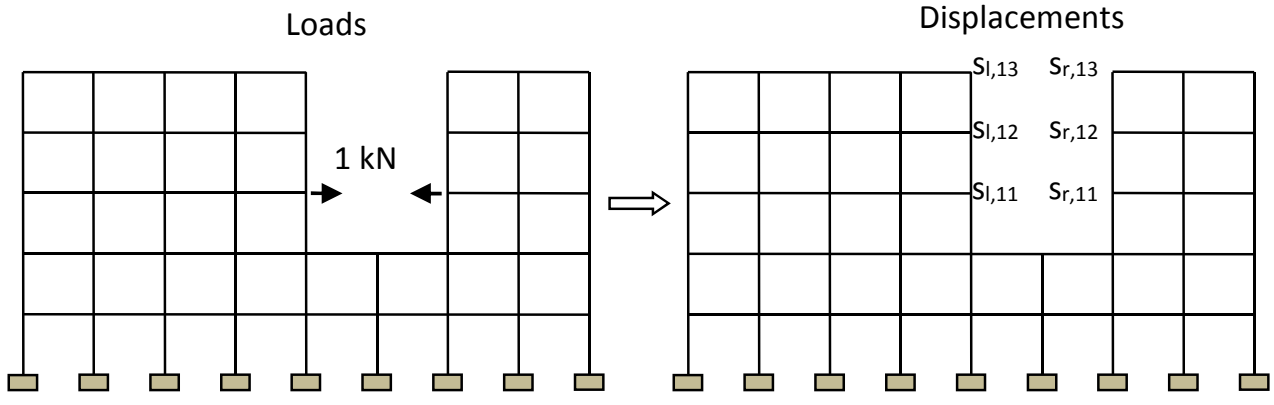

(b)

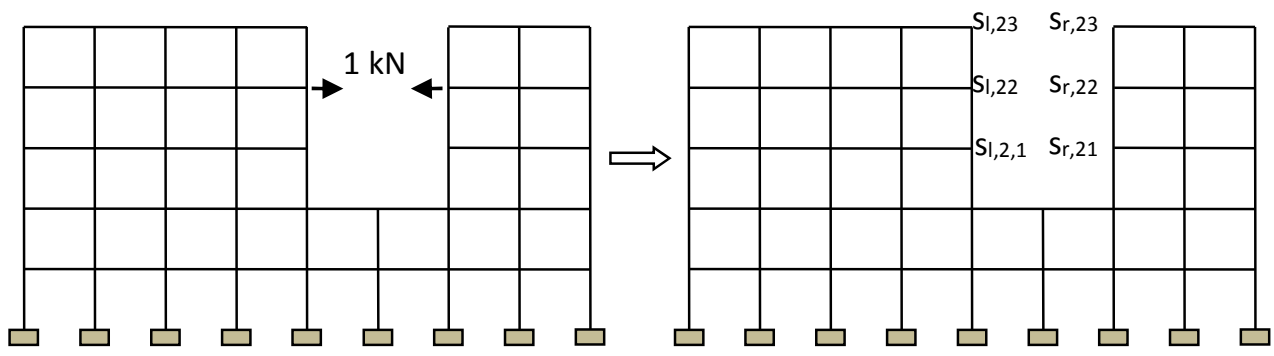

Figure 17. Definition of the $s_{i j}$ coefficients of the flexibility matrix

The input data for the final analytical model are given in Table 5. 
The validation of the proposed model has been done through several comparisons between numerical and analytical results for the frames shown in Figure 18. In these study cases, the beam-tocolumn joints are assumed to be full-strength and fully rigid. Finelg program [18] has been used for the numerical analysis. A good agreement is globally observed. A limited divergence of the curves can however be observed when significant membrane forces are developing. This can be explained through the following observation. In the analytical model, the length of the yielded zone is fixed from the beginning to the end of the curve (see Section 3.1.2) while, in the numerical model, the yielding can spread all along the beam. Accordingly, when significant plasticity is developing in the beams, a more flexible response is observed through the numerical model. However, it can be concluded that the analytical model is sufficiently accurate.

Table 5. Input data for the final analytical model

\begin{tabular}{|c|c|}
\hline $\begin{array}{l}\text { characteristics of the cross section of the beams }\left(A, I, W_{\mathrm{el}}\right. \\
\mathrm{W}_{\mathrm{pl}} \text {, dimensions, ...) }\end{array}$ & \multirow{3}{*}{$\begin{array}{l}\text { These parameters allow the } \\
\text { computation of the following } \\
\text { values: } L, h_{i} \text { of the springs, } A_{i} \text {, } \\
F_{\text {rdi, }} K_{i}\end{array}$} \\
\hline$L_{0}$ & \\
\hline$E, f_{y}$ & \\
\hline $\begin{array}{l}\mathrm{n}_{\mathrm{st}}=\text { number of stories of the DAP } \\
\mathrm{n}=\text { stories under the lost column }\end{array}$ & \\
\hline characteristics of the cross section of the columns & \\
\hline $\mathrm{c}=$ number of columns in the IAP (right and left) & \\
\hline
\end{tabular}




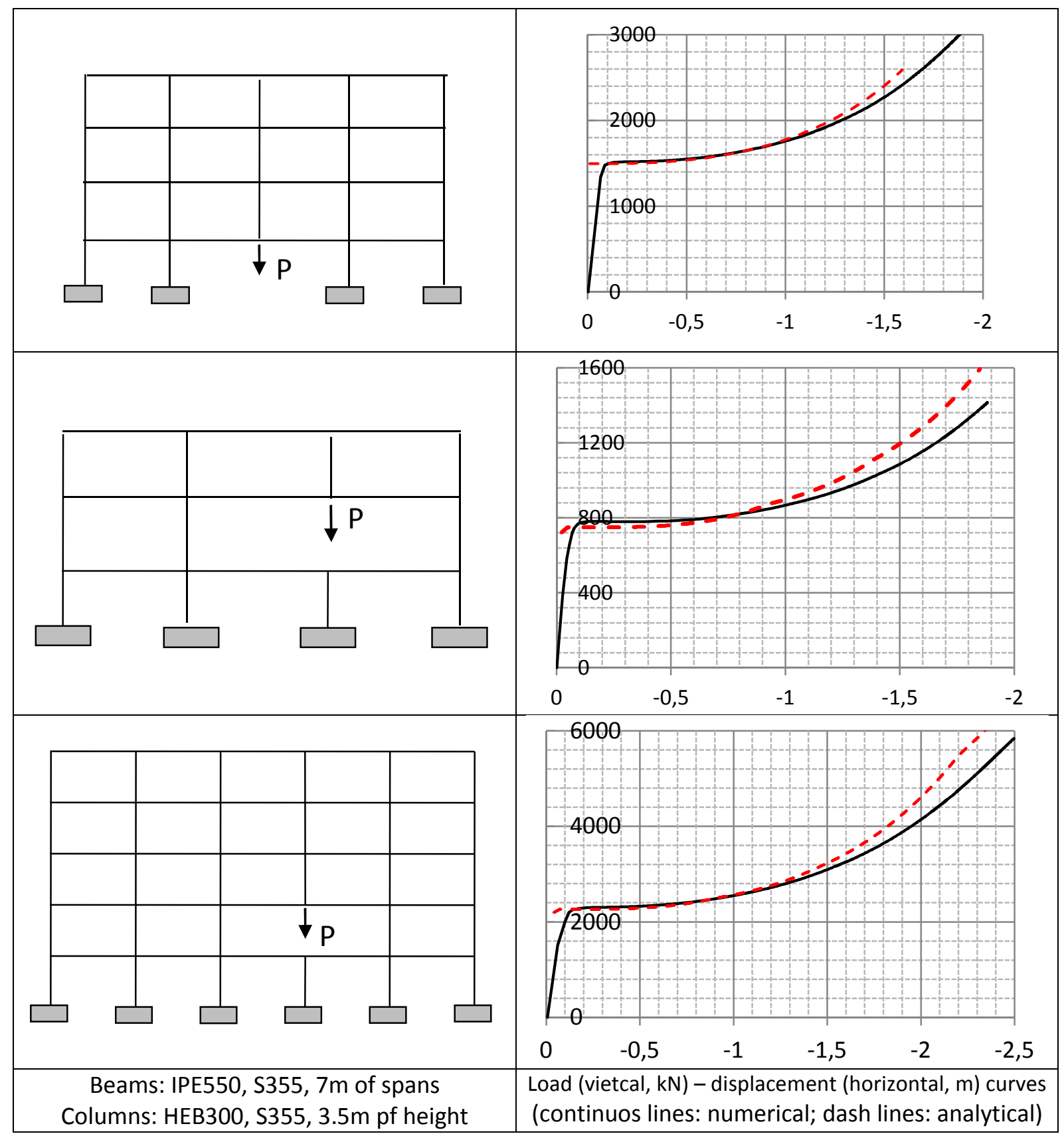

Figure 18. Validation of the analytical model through comparisons to numerical results 
Table 6. Unknowns and equations for the final analytical model

\begin{tabular}{|c|c|c|c|}
\hline Unknowns & Number & Equations & Number \\
\hline $\mathrm{u}$ & 1 & $\mathrm{u}=$ input data & 1 \\
\hline$\theta$ & $\mathrm{n}_{\mathrm{st}}$ & $\sin (\theta)=\mathrm{u} /\left(\mathrm{L}_{0}-2 \mathrm{~L}+\Delta_{\mathrm{L}}\right)$ & $\mathrm{n}_{\mathrm{st}}$ \\
\hline$\delta$ & $\mathrm{n}_{\mathrm{st}}$ & $\cos (\theta)=\left(\mathrm{L}_{0}-2 \mathrm{~L}-\delta_{\mathrm{H}}-2 \delta\right) /\left(\mathrm{L}_{0}-2 \mathrm{~L}+\Delta_{\mathrm{L}}\right)$ & $\mathrm{n}_{\mathrm{st}}$ \\
\hline$\delta_{H, I}$ & $\mathrm{n}_{\mathrm{st}}$ & $\delta_{H, l}\left(n_{s t} x 1\right)=S_{l}\left(n_{s t} n_{s t}\right) F_{H}\left(n_{s t}\right)$ & $\mathrm{n}_{\mathrm{st}}$ \\
\hline$\delta_{\mathrm{H}, \mathrm{r}}$ & $\mathrm{n}_{\mathrm{st}}$ & $\delta_{H, r}\left(n_{s t} 1\right)=S_{r}\left(n_{s t} n_{s t}\right) F_{H}\left(n_{s t}\right)$ & $\mathrm{n}_{\mathrm{st}}$ \\
\hline$\Delta_{\mathrm{L}}$ & $\mathrm{n}_{\mathrm{st}}$ & $\Delta_{\mathrm{L}}=\mathrm{F}_{\mathrm{H}}\left(\mathrm{L}_{0}-2 \mathrm{~L}\right) /(\mathrm{EA})$ & $\mathrm{n}_{\mathrm{st}}$ \\
\hline M & $\mathrm{n}_{\mathrm{st}}$ & $\mathrm{M}=\sum \mathrm{F}_{\mathrm{i}} \mathrm{h}_{\mathrm{i}}$ & $\mathrm{n}_{\mathrm{st}}$ \\
\hline $\mathrm{F}_{\mathrm{H}}$ & $\mathrm{n}_{\mathrm{st}}$ & $\mathrm{F}_{\mathrm{H}}=\sum \mathrm{F}_{\mathrm{i}}$ & $\mathrm{n}_{\mathrm{st}}$ \\
\hline $\mathrm{F}_{\mathrm{i}}(\mathrm{i}=[1: 6])$ & $6 * n_{s t}$ & $\mathrm{Fi}=\mathrm{f}\left(\delta_{\mathrm{i}}\right)$ & $6^{*} n_{\mathrm{st}}$ \\
\hline$\delta_{i}(i=[1: 6])$ & $6 * n_{s t}$ & $\delta_{i}=\delta+h_{i} \theta$ & $6^{*} n_{\mathrm{st}}$ \\
\hline$P$ & $\mathrm{n}_{\mathrm{st}}$ & $-0.5 \mathrm{P}\left(\mathrm{L}_{0}-0.5\left(\delta_{H, l}+\delta_{H, r}\right)\right)+\mathrm{F}_{H} \mathrm{u}+2 \mathrm{M}=0$ & $\mathrm{n}_{\mathrm{st}}$ \\
\hline$P_{\text {tot }}$ & 1 & $P_{\text {tot }}=\sum P$ & 1 \\
\hline
\end{tabular}

\section{Discussion and conclusion}

The full analytical method presented in this paper allows predicting the response of a frame submitted to a column loss. It has been shown in the paper that the analytical results are in good agreement with numerical and experimental results, for simple substructure as well as for complete frames. The developed method takes into account the following phenomena:

- the global interaction between the different parts of the structure;

- the local phenomena occurring in the yield zones, submitted to both $\mathrm{M}$ and $\mathrm{N}$.

The method presented here deals with 2D frames, submitted to a static column loss. Also, it is assumed that the indirectly affected part remains elastic and so the horizontal restraints brought by the indirectly affected part are constant during phase 3.

Other research works are now being conducted in Liege to deal with aspects such as the 3D structural response, the possible dynamic effects associated to an impact or a blast loading and the progressive yielding of the indirectly affected part ([10], [1] and [7] respectively). 
For the simulation of the joints, some simplifying assumptions have been made; for example, the group effects are not considered, the concrete in composite joints is assumed to have an infinite ductility and the shear interaction in the yield zones is neglected. These points are also being investigated further.

The final aim of these developments is to propose practical guidelines, design recommendations or easy-to-use software, founded on a good knowledge of the structural behaviour, and so to help practitioners facing robustness issues in design offices.

\section{Table of notations}

\begin{tabular}{|c|c|}
\hline $\mathrm{N}_{\mathrm{AB}}$ & Compression force in the column \\
\hline $\mathrm{N}_{\mathrm{AB}, \text { normal }}$ & Compression force in the column before it disappears \\
\hline $\mathrm{P}$ & Force simulating the loss of the column \\
\hline u & Vertical displacement at the top of the lost column \\
\hline $\mathrm{K}_{\mathrm{H}}$ & $\begin{array}{l}\text { Stiffness of the horizontal spring simulating the lateral restraint of the indirectly } \\
\text { affected part }\end{array}$ \\
\hline $\mathrm{F}_{\mathrm{H}}$ & Horizontal force acting on the spring $\mathrm{K}_{\mathrm{H}}$ \\
\hline$\delta_{H}$ & Horizontal elongation of the spring $\mathrm{K}_{\mathrm{H}}$ \\
\hline $\mathrm{K}_{\mathrm{N}}$ & Axial stiffness of a plastic hinge submitted to bending and axial force \\
\hline$\delta_{\mathrm{N}}$ & Axial elongation a plastic hinge submitted to bending and axial force \\
\hline $\mathrm{N}$ & Axial force in the beams of the directly affected part \\
\hline M & Bending moment at the extremities of the beams of the directly affected part \\
\hline$\theta$ & Rotation at the extremities of the beams of the directly affected part \\
\hline $\mathrm{L}_{0}$ & Initial length of the beams \\
\hline$\Delta \mathrm{L}$ & Elastic elongation of the beams of the directly affected part \\
\hline $\mathrm{L}$ & Length of the plastic hinge (plasticized zones) \\
\hline$s_{i j}$ & $\begin{array}{l}\text { Displacement at the storey i for a force acting at the level } \mathrm{j} \text { of the indirectly affected } \\
\text { part }\end{array}$ \\
\hline
\end{tabular}




\section{References}

[1] Comeliau L., Rossi B., Demonceau J.-F. Robustness of steel and composite buildings suffering the dynamic loss of a column. Structural Engineering International journal, Vol. 22/3, pp. 323-329, 2012.

[2] Demonceau J.-F., Comeliau L., Jaspart J.-P. Robustness of building structures - recent developments and adopted strategy. Steel Construction - Design and research, Vol. 4/2011, pp. 166-170, 2011.

[3] Demonceau J.-F., Jaspart J.-P. Experimental test simulation a column loss in a composite frame. in Advanced Steel Construction, 2010, Vol. 6, Fascicule 3, p. 891-913.

[4] Demonceau J.-F. Steel and composite building frames: sway response under conventional loading and development of membrane effects in beams further to an exceptional action. $\mathrm{PhD}$ thesis, University of Liege, 2008 (freely downloadable at: http://hdl.handle.net/2268/2740)

[5] Gerasimidis S. Analytical assessment of steel frames progressive collapse vulnerability to corner column loss. Journal of Constructional Steel Research 95 (2014) 1-9.

[6] Gerasimidis S., Baniotopoulos C.C. Evaluation of wind load integration in disproportionate collapse analysis of steel moment frames for column loss. Journal of Wind Engineering and Industrial Aerodynamics 99 (2011) 1162-1173.

[7] Huvelle C., Contribution to the study of the robustness of building structures: consideration of the yielding of the part of the structure which is not directly affected by the exceptional event (in French). Master thesis, University of Liege, 2011 (freely downloadable at http://hdl.handle.net/2268/127083).

[8] Huvelle C., Jaspart J.-P., Demonceau J.-F. Robustness of steel building structures following a column loss. Proceedings of IABSE Workshop "Safety, Failures and Robustness of Large Structures", Helsinki, 2013. 
[9] Izzuddin B.A. , Vlassis A.G., Elghazouli A.Y., Nethercot D.A. Progressive collapse of multi-storey buildings due to sudden column loss — Part I: Simplified assessment framework. Engineering Structures 30 (2008) 1308-1318.

[10] Lemaire F. Study of the 3D behaviour of steel or composite structures further to a column loss (in French). Master thesis, University of Liege, 2010.

[11] Luu N. N. H. Structural response of steel and composite building frames further to an impact leading to the loss of a column. PhD thesis, University of Liege, 2008.

[12] Vlassis A.G., Izzuddin B.A., Elghazouli A.Y., Nethercot D.A. Progressive collapse of multi-storey buildings due to sudden column loss-Part II: Application. Engineering Structures 30 (2008) $1424-1438$.

[13] Zolghadr Jahromi H., Vlassis A.G., Izzuddin B.A. Modelling approaches for robustness assessment of multi-storey steel-composite buildings. Engineering Structures 51 (2013) 278294.

[14]Cerfontaine F. Study of the interaction between bending moment and axial forces in bolted joints (in French), PhD thesis, University of Liege, 2004.

[15]Demonceau J.-F., Jaspart J.-P., Klinkhammer R., Weynand K., Labory F. , Cajot L.G. Recent developments on composite connections. Steel Construction - Design and Research Journal, Vol. 1, September 2008, pp. 71-76.

[16]Eurocode 3, Part 1-1. Eurocode 3: Design of steel structures - Part 1-1: General rules and rules for buildings. CEN, May 2005.

[17]Villette M. Critical analysis of the treatment of members subjected to compression and bending and propositions of new formulations (in French). PhD thesis, University of Liege, 2004.

[18]Finelg user's manual. Non-linear finite element analysis program. Version 9.0, University of Liege, 2003.

[19]Chen W.F., Yoshiaki Goto, Richard Liew J.Y. Stability Design of Semi-Rigid Frames. JOHN WILEY \& SONS, INC, 1996, p. 162-163. 
[20]KuhImann U., Rölle L., Jaspart J.-P., Demonceau J.-F., Vassart O., Weynand K. et al. Robust structure by joint ductility. Final report of the RFCS project nRFS-CR-04046, 2008.

[21]Eurocode 3, Part 1-8, Eurocode 3: Design of steel structure - Part 1-8: Design of joints. CEN, May 2005.

[22]Eurocode 4, Part 1-1, Eurocode 4: Design of composite steel and concrete structures - Part 1-1: General rules and rules for buildings. CEN, December 2004. 